\title{
Some Convergence Results for Modified S-Iterative Scheme in Hyperbolic Spaces
}

\author{
Renu Chugh, Preety and Madhu Aggarwal \\ Department of Mathematics, \\ Maharshi Dayanand University, \\ Rohtak-124001(INDIA)
}

\begin{abstract}
The aim of this paper is to prove strong and $\Delta$-convergence theorems of modified S-iterative scheme for asymptotically quasi-nonexpansive mapping in hyperbolic spaces. The results obtained generalize several results of uniformly convex Banach spaces and CAT $(0)$ spaces.
\end{abstract}

\section{Keywords-}

Hyperbolic space, fixed point, asymptotically quasi nonexpansive mapping, strong convergence, $\Delta$-convergence.

\section{INTRODUCTION AND PRELIMINARIES}

In 1970, Takahashi [11] introduced the notion of convex metri $\mathrm{c}$ space and studied the fixed point theorems for nonexpansive mappings. He defined that a map $W: X^{2} \times[0,1] \rightarrow X$ is a convex structure in $\mathrm{X}$ if

$$
d(u, W(x, y, \lambda)) \leq \lambda d(u, x)+(1-\lambda) d(u, y)
$$

for all $x, y, u \in X$ and $\lambda \in[0,1]$. A metric space $(X, d)$ together with a convex structure $W$ is known as convex metric space and is denoted by $(X, d, W)$. A nonempty subset $C$ of a convex metric space is convex if $W(x, y, \lambda) \in C$ for all $x, y \in C$ and $\lambda \in[0,1]$.

After that several authors extended this concept in many ways. One such convex structure is hyperbolic space which was introduced by Kohlenbach [9] as follows:

A hyperbolic space $(X, d, W)$ is a metric space $(X, d)$ together with a convexity mapping $W: X \times X \times[0,1] \rightarrow X$ satisfying

(W1) $\quad d(z, W(x, y, \lambda)) \leq(1-\lambda) d(z, x)+\lambda d(z, y)$

(W2) $d\left(W\left(x, y, \lambda_{1}\right), W\left(x, y, \lambda_{2}\right)\right)=\left|\lambda_{1}-\lambda_{2}\right| d(x, y)$

(W3) $\quad W(x, y, \lambda)=W(y, x, 1-\lambda)$

(W4) $\quad d(W(x, z, \lambda), W(y, w, \lambda)) \leq(1-\lambda) d(x, y)+\lambda d(z, w)$

for all $x, y, z, w \in X$ and $\lambda, \lambda_{1}, \lambda_{2} \in[0,1]$.

Clearly every hyperbolic space is convex metric space but converse need not true. For example, if $\mathrm{X}=\mathrm{R}$ (the set of reals), $W(x, y, \lambda)=\lambda x+(1-\lambda) y$ and define $d(x, y)=\frac{|x-y|}{1+|x-y|}$ for $x, y \in R$, then $(X, d, W)$ is a convex metric space but not a hyperbolic space.

The class of Hyperbolic spaces includes normed spaces, CAT(0) spaces, Hadmard manifolds, R-trees and Hilbert balls.
A hyperbolic space $(X, d, W)$ is said to be uniformly convex [8] if for all $u, x, y \in X, r>0$ and $\varepsilon \in(0,2]$ , there exists a $\delta \in(0,1]$ such that $d\left(W\left(x, y, \frac{1}{2}\right), u\right) \leq(1-\delta) r$ ,whenever $\quad d(x, u) \leq r, d(y, u) \leq r$ and $d(x, y) \geq \varepsilon r$.

A map $\eta:(0, \infty) \times(0,2] \rightarrow(0,1]$ which provides such a $\delta=\eta(r, \varepsilon)$ for $u, x, y \in X, r>0$ and $\varepsilon \in(0,2]$ is called modulus of uniform convexity of X. We call $\eta$ to be monotone if it decreases with $\mathrm{r}$ (for a fixed $\varepsilon$ ).

A Sequence $\left\{x_{n}\right\}$ in $(X, d)$ is Fejer monotone with respect to a subset $\mathrm{K}$ of $\mathrm{X}$ if

$$
d\left(x_{n}, x\right) \leq d\left(x_{n-1}, x\right) \quad \text { for all } x \in K .
$$

Let $\left\{x_{n}\right\}$ be a bounded sequence in a metric space $\mathrm{X}$. We define a functional $r\left(.,\left\{x_{n}\right\}\right): X \rightarrow R^{+} \quad$ by $r\left(x,\left\{x_{n}\right\}\right)=\limsup _{n \rightarrow \infty} d\left(x, x_{n}\right)$ for all $x \in K$.The asymptotic radius of $\left\{x_{n}\right\}$ with respect to $K \subseteq X$ is defined as, $r\left(\left\{x_{n}\right\}\right)=\inf \left\{r\left(x,\left\{x_{n}\right\}\right): x \in K\right\}$.

A point $y \in K$ is called the asymptotic centre of $\left\{x_{n}\right\}$ with respect to $K \subseteq X$ if

$r\left(y,\left\{x_{n}\right\}\right) \leq r\left(x,\left\{x_{n}\right\}\right)$ for all $x \in K$. The set of all asymptotic centres of $\left\{x_{n}\right\}$ is denoted by $A\left(\left\{x_{n}\right\}\right)$.

Leustean [6] showed that bounded sequences have $\mathrm{u}$ nique asymptotic centre with respect to closed convex subsets in a complete and uniformly convex hyperbolic space with monotone modulus of uniform convexity.

A sequence $\left\{x_{n}\right\}$ in $\mathrm{X}$ is said to $\Delta$-converge to $x \in X$ if $\mathrm{x}$ is the unique asymptotic centre of $\left\{u_{n}\right\}$ for every subsequence $\left\{u_{n}\right\}$ of $\left\{x_{n}\right\}$ [11]. In this case, we write $\mathrm{X}$ as $\Delta$ - limit of $\left\{x_{n}\right\}$, i.e., $\Delta-\lim _{n} x_{n}=x$.

Also $\Delta$-convergence coincides with weak convergence in Banach spaces with opial's property [7].

Definition1.1. Let $(X, d, W)$

be a hyperbolic space, $\mathrm{C}$ be a convex subset of $X$.

Then $T: C \rightarrow C$ is

(1) nonexpansive if $d(T x, T y) \leq d(x, y)$

for all $x, y \in C$.

(2) quasi-nonexpansive if $d(T x, p) \leq d(x, p)$ for all $x \in C$ and $p \in F(T)$. 
(3) asymptotically nonexpansive if there exists a sequence $\left\{k_{n}\right\}, k_{n} \geq 1$, with $\lim _{n \rightarrow \infty} k_{n}=1 \quad$ and $d\left(T^{n} x, T^{n} y\right) \leq k_{n} d(x, y) \quad$ for all $x, y \in C$ and $n \in N$. Note that $\left\{k_{n}\right\}$ is a non-increasing bounded sequence.

(4) Asymptotically quasi-nonexpansive if there exists a sequence $\left\{k_{n}\right\}, k_{n} \geq 1$

, with $\lim _{n \rightarrow \infty} k_{n}=1$ and $\quad d\left(T^{n} x, p\right) \leq k_{n} d(x, p)$ for all $x \in C, p \in F(T)$ and $n \in N$.

(5) uniformly L-Lipschitzian if there exists a constant $L>0$ such that

$d\left(T^{n} x, T^{n} y\right) \leq L d(x, y)$ for all $x, y \in C$ and $n \in N$.

It should be noted that a nonexpansive mapping must $\mathrm{b}$ e a quasi-nonexpansive and an expansive mapping must be asymptotically quasi-

nonexpansive. But converse does not necessary hold.

A mapping $T: C \rightarrow C$ is said to be demiclosed at zero, if for any sequence $\left\{x_{n}\right\}$ in $\mathrm{C}$, the conditions $x_{n}$ converges weakly to $x \in C$ and $T x_{n}$ converges strongly to 0 imply $T x=0$.

In 1974, Senter and Doston [2] defined that a mapping $T: C \rightarrow C$, where $\mathrm{C}$ is a subset of a hyperbolic space $\mathrm{E}$, is said to satisfy the condition (A) if there exists a nondecreasing function $f:[0, \infty) \rightarrow[0, \infty)$ with

$f(0)=0, f(r)>0$ for all $r \in(0, \infty)$

such that $d(x, T x) \geq f(d(x, F(T))) \quad$ for $\quad$ all $x \in C$ where $d(x, F(T))=\inf \{d(x, p): p \in F(T)\}$ and $\mathrm{F}(\mathrm{T})$ denotes the set of fixed points of $T$.

Now we give some well known iterative schemes in hyperbolic spaces :

(1.1.1) Modified Picard iterative scheme:

$x_{n+1}=T^{n} x_{n}, n \in N$.

(1.1.2) Modified Mann iterative scheme [3]:

$x_{n+1}=W\left(x_{n}, T^{n} x_{n}, \alpha_{n}\right), n \in N$

where $\alpha_{n} \in[0,1]$

(1.1.3) Modified Ishikawa iterative scheme [4]:

$$
\begin{aligned}
& x_{n+1}=W\left(x_{n}, T^{n} y_{n}, \alpha_{n}\right), \\
& y_{n}=W\left(x_{n}, T^{n} x_{n}, \beta_{n}\right), n \in N \\
& \text { where } \alpha_{n}, \beta_{n} \in[0,1]
\end{aligned}
$$

(1.1.4) Modified S-iterative scheme [5]:

$$
\begin{aligned}
& x_{n+1}=W\left(T^{n} x_{n}, T^{n} y_{n}, \alpha_{n}\right), \\
& y_{n}=W\left(x_{n}, T^{n} x_{n}, \beta_{n}\right), n \in N \\
& \text { where } \alpha_{n}, \beta_{n} \in[0,1] .
\end{aligned}
$$

In 2007, Agarwal et. al.[5] showed that the iterative scheme (1.1.4) converges at a rate similar to the Picard iteration and faster than Mann iteration for contractions.

Many authors have studied the strong and $\Delta-$ convergence of various iterative schemes in hyperbolic spaces (see $[1,6])$. The purpose of this paper is to obtain $\Delta-$ convergence as well as strong convergence results of modified $\mathrm{S}$ - iterative procedure for asymptotically quasi- nonexpansive mapping in hyperbolic spaces.

We need the following Lemmas to prove our main result.

Lemma 1.1 ([4]) If $\left\{r_{n}\right\},\left\{t_{n}\right\}$ and $\left\{s_{n}\right\}$ are sequences of nonnegative real numbers such that $r_{n+1}<\left(1+t_{n}\right) r_{n}+s_{n}, \sum_{n=1}^{\infty} t_{n}<\infty$ and $\sum_{n=1}^{\infty} s_{n}<\infty$, then $\lim _{n \rightarrow \infty} r_{n}$ exists.

Lemma 1.2 ([1]) Let $\mathrm{K}$ be a nonempty closed convex subset of a uniformly convex hyperbolic space and $\left\{x_{n}\right\}$ be a bounded sequence in $\mathrm{K}$ such that $A\left(\left\{x_{n}\right\}\right)=\{y\}$. If $\left\{y_{m}\right\}$ is another sequence in $\mathrm{K}$ such that $\lim _{m \rightarrow \infty} r\left(y_{m},\left\{x_{n}\right\}\right)=\rho$ (a real number), then $\lim _{m \rightarrow \infty} y_{m}=y$.

Lemma 1.3 ([1]) Let $(X, d, W)$ be a uniformly convex hyperbolic space with monotone modulus of uniform convexity $\eta$. Let $x \in X$ and $\left\{a_{n}\right\} \quad$ be a sequence in $[\mathrm{b}, \mathrm{c}]$ for some $b, c \in[0,1]$. If $\left\{w_{n}\right\}$ and $\left\{z_{n}\right\}$ are sequences in $\mathrm{X}$ such that $\limsup _{n \rightarrow \infty} d\left(w_{n}, x\right) \leq r$, $\limsup _{n \rightarrow \infty} d\left(z_{n}, x\right) \leq r$ and $\lim _{n \rightarrow \infty} d\left(W\left(w_{n}, z_{n}, a_{n}\right), x\right)=r$ for some $r \geq 0$, then $\lim _{n \rightarrow \infty} d\left(w_{n}, z_{n}\right)=0$.

\section{CONVERGENCE RESULTS}

Lemma 2.1 Let $C$ be a nonempty closed convex subset of a convex hyperbolic space $\mathrm{E}$. Let $\mathrm{T}$ be asymptotically quasinonexpansive self mapping of $\mathrm{C}$ with $\sum_{n=1}^{\infty}\left(k_{n}-1\right)<\infty$. Let $\left\{x_{n}\right\}$ be defined by (1.1.4) and $F(T) \neq \phi$ . Then $\lim _{n \rightarrow \infty} d\left(x_{n}, q\right)$ exists for all $q \in F(T)$.

Proof: Let $q \in F(T)$. Then

$$
\begin{aligned}
& d\left(x_{n+1}, q\right)=d\left(W\left(T^{n} x_{n}, T^{n} y_{n} ; \alpha_{n}\right), q\right) \\
\leq & \left(1-\alpha_{n}\right) d\left(T^{n} x_{n}, q\right)+\alpha_{n} d\left(T^{n} y_{n}, q\right) \\
\leq & \left(1-\alpha_{n}\right) k_{n} d\left(x_{n}, q\right)+\alpha_{n} k_{n} d\left(y_{n}, q\right) \\
= & {\left[\left(1-\alpha_{n}\right) k_{n} d\left(x_{n}, q\right)\right]+\alpha_{n} k_{n} d\left(W\left(x_{n}, T^{n} x_{n} ; \beta_{n}\right), q\right) } \\
\leq & \left(1-\alpha_{n}\right) k_{n} d\left(x_{n}, q\right)+\alpha_{n} k_{n}\left[\left(1-\beta_{n}\right) d\left(x_{n}, q\right)+\beta_{n} d\left(T^{n} x_{n}, q\right)\right] \\
= & k_{n}\left[\left(1-\alpha_{n}\right) d\left(x_{n}, q\right)+\alpha_{n}\left(1-\beta_{n}\right) d\left(x_{n}, q\right)+\alpha_{n} \beta_{n} d\left(T^{n} x_{n}, q\right)\right. \\
\leq & k_{n}\left[\left(1-\alpha_{n}\right) d\left(x_{n}, q\right)+\alpha_{n}\left(1-\beta_{n}\right) d\left(x_{n}, q\right)+k_{n} \alpha_{n} \beta_{n} d\left(x_{n}, q\right)\right. \\
\leq & k_{n}\left[\left(1-\alpha_{n}+\alpha_{n}\left(1-\beta_{n}\right)+k_{n} \alpha_{n} \beta_{n}\right) d\left(x_{n}, q\right)\right] \\
= & k_{n}\left[\left(1+\left(k_{n}-1\right) \alpha_{n} \beta_{n}\right] d\left(x_{n}, q\right)\right. \\
\leq & k_{n}\left[1+k_{n}-1\right] d\left(x_{n}, q\right) \\
= & {\left[1+\left(k_{n}^{2}-1\right)\right] d\left(x_{n}, q\right) . }
\end{aligned}
$$

Since $\left\{k_{n}\right\}$ and hence $\left\{k_{n}+1\right\}$

is a nonincreasing bounded sequence, $\sum_{n=1}^{\infty}\left(k_{n}-1\right)<\infty$ implies that $\sum_{n=1}^{\infty}\left(k_{n}^{2}-1\right)<\infty$. It now follows from Lemma 1.1 that $\lim _{n \rightarrow \infty} d\left(x_{n}, q\right)$ exists for all $q \in F(T)$.

Theorem 2.2. Let $\mathrm{C}$ be a nonempty closed convex subset of a uniformly convex hyperbolic space $\mathrm{E}$. Let $\mathrm{T}$ be uniformly Lipschitzian and asymptotically quasi-nonexpansive self mapping of $\mathrm{C}$ with $\quad \sum_{n=1}^{\infty}\left(k_{n}-1\right)<\infty . \quad$ Let $\left\{x_{n}\right\}$ be defined by (1.1.4) and $F(T) \neq \phi$.

Then $\lim _{n \rightarrow \infty} d\left(x_{n}, T x_{n}\right)=0$.

Proof: By Lemma 2.1, $\lim _{n \rightarrow \infty} d\left(x_{n}, q\right)$ exists. 
Assume that $\lim _{n \rightarrow \infty} d\left(x_{n}, q\right)=c$. If $c=0$, the conclusion is obvious.

Suppose $c>0$. Now,

$$
\begin{aligned}
d\left(y_{n}, q\right)= & d\left(W\left(x_{n}, T^{n} x_{n} ; \beta_{n}\right), q\right) \\
& \leq\left(1-\beta_{n}\right) d\left(x_{n}, q\right)+\beta_{n} d\left(T^{n} x_{n}, q\right) \\
& \leq\left(1-\beta_{n}\right) d\left(x_{n}, q\right)+k_{n} \beta_{n} d\left(x_{n}, q\right) \\
& \leq\left(1+\beta_{n}\left(k_{n}-1\right)\right) d\left(x_{n}, q\right)
\end{aligned}
$$

implies that

$\limsup _{n \rightarrow \infty} d\left(y_{n}, q\right) \leq c$.

Since $\mathrm{T}$ is an asymptotically quasi-nonexpansive mapping, we have

$d\left(T^{n} x_{n}, q\right) \leq k_{n} d\left(x_{n}, q\right)$

for $n \in N$. Thus,

$\limsup _{n \rightarrow \infty} d\left(T^{n} x_{n}, q\right) \leq c$.

Similarly, we get

$d\left(T^{n} y_{n}, q\right) \leq k_{n} d\left(y_{n}, q\right)$.

Now using (2.1.1), we obtain

$\limsup _{n \rightarrow \infty} d\left(T^{n} y_{n}, q\right) \leq c$.

Also it follows from

$c=\lim _{n \rightarrow \infty} d\left(x_{n+1}, q\right)=\lim _{n \rightarrow \infty} d\left(W\left(T^{n} x_{n}, T^{n} y_{n} ; \alpha_{n}\right), q\right)$ and

Lemma 1.2 that

$\lim _{n \rightarrow \infty} d\left(T^{n} x_{n}, T^{n} y_{n}\right)=0$.

Now

$d\left(x_{n+1}, q\right)=d\left(W\left(T^{n} x_{n}, T^{n} y_{n} ; \alpha_{n}\right), q\right)$

$\leq\left(1-\alpha_{n}\right) d\left(T^{n} x_{n}, q\right)+\alpha_{n} d\left(T^{n} y_{n}, q\right)$

$\leq\left(1-\alpha_{n}\right) d\left(T^{n} x_{n}, q\right)+\alpha_{n}\left[d\left(T^{n} y_{n}, T^{n} x_{n}\right)+d\left(T^{n} x_{n}, q\right)\right]$

yields that

$c \leq \liminf _{n \rightarrow \infty} d\left(T^{n} x_{n}, q\right)$

so from (2.1.2), we get $\lim _{n \rightarrow \infty} d\left(T^{n} x_{n}, q\right)=c$.

On the other hand,

$d\left(T^{n} x_{n}, q\right) \leq d\left(T^{n} x_{n}, T^{n} y_{n}\right)+d\left(T^{n} y_{n}, q\right)$

$$
\leq d\left(T^{n} x_{n}, T^{n} y_{n}\right)+k_{n} d\left(y_{n}, q\right) .
$$

So we have,

$c \leq \liminf _{n \rightarrow \infty} d\left(y_{n}, q\right)$

By using (2.1.1) and (2.1.4), we get

$\lim _{n \rightarrow \infty} d\left(y_{n}, q\right)=c$.

Thus $c=\lim _{n \rightarrow \infty} d\left(y_{n}, q\right)=\lim _{n \rightarrow \infty} d\left(W\left(x_{n}, T^{n} x_{n} ; \beta_{n}\right), q\right)$ gives

by Lemma 1.2 that $\lim _{n \rightarrow \infty} d\left(T^{n} x_{n}, x_{n}\right)=0$

Also,

$$
\begin{aligned}
& d\left(x_{n+1}, x_{n}\right)=d\left(W\left(T^{n} x_{n}, T^{n} y_{n} ; \alpha_{n}\right), x_{n}\right) \\
& \leq\left(1-\alpha_{n}\right) d\left(T^{n} x_{n}, x_{n}\right)+\alpha_{n} d\left(T^{n} y_{n}, x_{n}\right)
\end{aligned}
$$

$\leq\left(1-\alpha_{n}\right) d\left(T^{n} x_{n}, x_{n}\right)+\alpha_{n}\left[d\left(T^{n} y_{n}, T^{n} x_{n}\right)+d\left(T^{n} x_{n}, x_{n}\right)\right]$

Thus,

$\lim _{n \rightarrow \infty} d\left(x_{n+1}, x_{n}\right)=0$.

Now,

$$
\begin{aligned}
& d\left(x_{n+1}, T x_{n+1}\right) \leq d\left(x_{n+1}, T^{n+1} x_{n+1}\right)+d\left(T^{n+1} x_{n+1}, T^{n+1} x_{n}\right) \\
& \quad+d\left(T^{n+1} x_{n}, T x_{n+1}\right) \\
& \leq d\left(x_{n+1}, T^{n+1} x_{n+1}\right)+\operatorname{Ld}\left(x_{n+1}, x_{n}\right)+\operatorname{Ld}\left(T^{n} x_{n}, x_{n+1}\right) \\
& \quad=d\left(x_{n+1}, T^{n+1} x_{n+1}\right)+\operatorname{Ld}\left(x_{n+1}, x_{n}\right)+\operatorname{L\alpha } \alpha_{n} d\left(T^{n} x_{n}, T^{n} y_{n}\right)
\end{aligned}
$$

yields $\lim _{n \rightarrow \infty} d\left(x_{n}, T x_{n}\right)=0$.

Theorem 2.3 Let E be a uniformly convex hyperbolic space and let $C, T$ and $\left\{x_{n}\right\}$ be taken as in Theorem 2.2. If the mapping $I-T$ is demiclosed at zero and $F(T) \neq \phi$, then the sequence $\left\{x_{n}\right\}$ in (1.1.4), $\Delta-$ converges to a fixed point of T. Proof: From Lemma $2.1 \lim _{n \rightarrow \infty} d\left(x_{n}, q\right)$ exists for all $q \in F(T)$. Thus $\left\{x_{n}\right\}$ is bounded. Therefore $\left\{x_{n}\right\}$ has a unique asymptotic centre, that is, $A\left\{x_{n}\right\}=q$. Let $\left\{x_{n_{k}}\right\}$ be any subsequence of $\left\{x_{n}\right\}$ such that $A\left(\left\{x_{n_{k}}\right\}\right)=\left\{q^{\prime}\right\}$. Thus by Theorem 2.2, we have $\lim _{n \rightarrow \infty} d\left(x_{n_{k}}, T x_{n_{k}}\right)=0$. Also mapping $I-T$ is demiclosed at zero, therefore $T q^{\prime}=q^{\prime}=S q^{\prime}$, that is $q^{\prime} \in F(T)$.

Let us suppose that $q=q^{\prime}$. Since by Lemma 2.1, $\lim _{n \rightarrow \infty} d\left(x_{n}, q^{\prime}\right)$ exists, so by using the uniqueness of asymptotic centre, we have,

$$
\begin{aligned}
\limsup _{n \rightarrow \infty} d\left(x_{n_{k}}, q^{\prime}\right) & <\lim _{n \rightarrow \infty} \sup d\left(x_{n_{k}}, q\right) \\
& \leq \lim _{n \rightarrow \infty} \sup d\left(x_{n}, q\right) \\
& <\lim _{n \rightarrow \infty} \sup d\left(x_{n}, q^{\prime}\right) \\
& =\lim _{n \rightarrow \infty} \sup d\left(x_{n_{k}}, q^{\prime}\right),
\end{aligned}
$$

which is a contradiction. Hence $q=q^{\prime}$. Therefore $A\left(\left\{x_{n_{k}}\right\}\right)=\{q\}$ for all subsequences $\left\{x_{n_{k}}\right\}$ of $\left\{x_{n}\right\}$. Thus $\left\{x_{n}\right\}$ $\Delta$ - converges to a fixed point of $\mathrm{T}$.

Theorem 2.4 Let E be a convex Hyperbolic space and let $C, T,\left\{x_{n}\right\}$ be taken as in Theorem 2.2. Then $\left\{x_{n}\right\}$ converges to a point of $F(T)$ if and only if $\lim _{n \rightarrow \infty} d\left(x_{n}, F(T)\right)=0$,

where $d(x, F(T))=\inf \{d(x, p) ; p \in F(T)\}$.

Proof: Necessity is obvious. Conversely, suppose that $\liminf _{n \rightarrow \infty} d\left(x_{n}, F(T)\right)$ exists. But by

hypothesis, $\liminf _{n \rightarrow \infty} d\left(x_{n}, F(T)\right)=0$,

therefore we have $\lim _{n \rightarrow \infty} d\left(x_{n}, F(T)\right)=0$. Next we show that $\left\{x_{n}\right\}$ is a Cauchy sequence in C. Let $\in>0$ be arbitrary chosen. Since $\quad \lim _{n \rightarrow \infty} d\left(x_{n}, F(T)\right)=0$ , there exists a positive integer $n_{0}$ such that

$$
d\left(x_{n}, F(T)\right)<\frac{\varepsilon}{4} \text {, for all } n \geq n_{0} .
$$

In particular, $\inf \left\{d\left(x_{n_{0}}, p\right): p \in F(T)\right\}<\frac{\varepsilon}{4}$.

Thus there must exists $p^{*} \in F(T)$ such that $d\left(x_{n_{0}}, p^{*}\right)<\frac{\varepsilon}{2}$.

Now for all $m, n \geq n_{0}$, we have

$$
\begin{aligned}
d\left(x_{n+m}, x_{n}\right) \leq & d\left(x_{n+m}, p^{*}\right)+d\left(x_{n}, p^{*}\right) \\
\leq & 2 d\left(x_{n_{0}}, p^{*}\right) \\
& <2\left(\frac{\varepsilon}{2}\right)=\varepsilon .
\end{aligned}
$$

Hence $\left\{x_{n}\right\}$ is a Cauchy sequence in a closed subset $\mathrm{C}$ of a convex Hyperbolic space $\mathrm{E}$ and so it must converge to a point $\mathrm{q}$ in C. Now, $\lim _{n \rightarrow \infty} d\left(x_{n}, F(T)\right)=0$ gives that $d(q, F(T))=0$. Since $\mathrm{F}(\mathrm{T})$ is closed, so we have $q \in F(T)$. 
Theorem 2.5 Let E be a uniformly convex Hyperbolic space and let $C, T,\left\{x_{n}\right\}$ be taken as in Theorem 2.2. Let T satisfy the condition (A), then $\left\{x_{n}\right\}$ converges strongly to a fixed point of $\mathrm{T}$.

Proof: We have proved in Theorem 2.2 that

$\lim _{n \rightarrow \infty} d\left(x_{n}, T x_{n}\right)=0$

From the condition (A) and (2.4.1), we have

$\lim _{n \rightarrow \infty} f\left(d\left(x_{n}, F(T)\right)\right) \leq \lim _{n \rightarrow \infty} d\left(x_{n}, T x_{n}\right)=0$,

Hence $\lim _{n \rightarrow \infty} f\left(d\left(x_{n}, F(T)\right)\right)=0$. Since $f:[0, \infty) \rightarrow[0, \infty)$

is a nondecreasing function satisfying $f(0)=0, f(r)>0$ for all $r \in(0, \infty)$, therefore we have $\lim _{n \rightarrow \infty} d\left(x_{n}, F(T)\right)=0$.

Now all conditions of Theorem (2.3) are satisfied, therefore by its conclusion $\left\{x_{n}\right\}$ converges strongly to a point of $F(T)$.

\section{CONCLUSION}

From the above discussion, it is clear that our results are quite simple, general and includes several theorems in Banach spaces and Hyperbolic spaces as special cases. The results of this paper can be extended to three step and multistep iterative procedures in Hyperbolic metric spaces.

\section{ACKNOWLEDGEMENT}

The third author gratefully acknowledges University Grants Commission for providing financial assistance under Basic Scientific Research Fellowship.

\section{REFERENCES}

[1] A. R. Khan, H.Fukhar-ud-din and M. A. Khan: An implicit algorithm for two finite families of nonexpansive maps in hyperbolic spaces, Fixed Point Theory Appl., vol.54, (2012), 12 pages.
[2] H. F. Senter and W. G. Dotson: Approximating fixed points of nonexpansive mappings, Proc. Amer. Math. Soc., vol. 44, (1974), 375-380.

[3] J. Schu, Weak and strong convergence to fixed points of asymptotically nonexpansive mappings, Bull. Austral. Math. Soc., vol. 43, (1991), 153-159.

[4] K. K. Tan and H. K. Xu: Approximating fixed points of nonexpansive mappings by Ishikawa iteration process, $\mathrm{J}$, Math. Anal., vol. 178, (1993), 301-308.

[5] R. P. Agarwal, D. O'Regan, and D. R. Sahu, Iterative construction of fixed points of nearly asymptotically nonexpansive mappings, J. Nonlinear Convex Anal., vol. 8, no. 1, (2007), 61-79.

[6] L. Leustean: Nonexpansive iterations in uniformly convex W-hyperbolic spaces, Contemp. Math., vol. 513, (2010), 193-210.

[7] T. Kuczumow: An almost convergence and its applications, Ann. Univ. Mariae Curie-Sklodowska, Sect. A., vol. 32, (1978),79-88.

[8] T. Shimizu and W. Takahashi: Fixed points of multivalued mappings in certain convex metric spaces, Topol. Methods Nonlinear Anal., vol. 8, (1996), $197-$ 203.

[9] U. Kohlenbach: Some logical metatheorems with applications in functional analysis, Trans. Amer. Math. Soc., vol. 357(2005), 89-128.

[10] W. Kirk and B. Panyanak: A concept of convergence in geodesic spaces, Nonlinear Anal., vol. 68, (2008), 36893696.

[11] W. Takahashi: A convexity in metric spaces and nonexpansive mapping, Kodai Math. Sem. Rep., vol. 22, (1970), 142-149. 